Original Research Paper

\title{
Sustainable Study of Self-Healing Concrete in Hot Desert Climate
}

\author{
${ }^{1}$ Batoul Chamali, ${ }^{2}$ Moayyad Al-Nasra and ${ }^{3}$ Taher M. Abu-Lebdeh \\ ${ }^{I}$ N. \& A. Inc., Dallas, North Carolina, USA \\ ${ }^{2}$ Civil Engineering Program, Shippensburg University of Pennsylvania, Pennsylvania, USA \\ ${ }^{3}$ Department of Civil, Architectural and Environmental Engineering, \\ North Carolina A\&T State University, Greensboro, NC 27411, USA
}

Article history

Received: 28-04-2019

Revised: 08-05-2019

Accepted: 14-05-2019

Corresponding Author:

Taher Abu-Lebdeh

Department of Civil,

Architectural and

Environmental Engineering,

North Carolina A\&T State

University, Greensboro, NC

27411, USA

Email: taher@ncat.edu

\begin{abstract}
The hot and dry desert climate is characterized by high temperature and high humidity. This affects the strength of concrete negatively by the difficulty of providing proper curing and by generating early micro-cracks due to the high temperature. These two issues have been addressed in this study by adding calcite precipitating bacteria to deal with the micro-cracks and by adding Ultra-High Absorbent Polymer (UHAP) to provide the concrete with the needed internal curing. Durability of concrete is what categorizes it as an effective construction material. Durability of the concrete is vastly affected by micro-cracks and macro cracks. Concrete is very strong in handling compressive stresses but on the other hand, it is quite weak when it comes to tensile stresses. While cracks caused by the increase in tensile stresses may cause structural failure, micro-cracks should also be taken into consideration. They cause higher permeability and durability concerns, leading to corrosion of reinforced steel bars. In addition, micro-cracks propagate to become macro cracks that induce failure in structural members. In a humid desert environment such as the UAE environment, micro-cracks are very influential in structures as they provide channels for moisture leading to significant damage. New environmentally friendly methods must be implemented in order to reduce micro-cracks in early stages before they expand and before they require maintenance. Thus, in this study, the effect of adding selfhealing agents in the concrete mix is investigated. The two measures considered in this study projected positive impact on the concrete compressive strength in the hot and dry desert climate.
\end{abstract}

Keywords: Calcite Precipitating Bacteria, Self-Healing Concrete, UltraHigh Absorbent Polymer, Hot Climate Concrete

\section{Introduction}

Concrete is the cornerstone of construction material in most structures since the beginning of human civilization. Although, concrete seems to be tough material, it is greatly affected by the ambient conditions that may lead to major issues. The production of cement, which is one of the main ingredients in concrete, contributes to around 5\% of Carbon Dioxide emissions around the globe. Thus, sustainable selfhealing concrete is necessary nowadays. It not only cuts down the amount of money spent on future maintenance but also in this case it directly reduces the cement production. Sealing cracks in concrete increases durability by preventing varies agents from penetrating into the concrete mass to weaken the core of the structure. In addition, the corrosion of the steel that carries tension forces begins with the cracks that allow the water to react with the embedded steel leading to tension failure. This has the potential to compromise the safety of the structure. Adding a biological agent to concrete to heal itself as a living creature, increases its life span. Previous studies on self-healing concrete showed that using an alkaline resistant bacterium results 
in sealing cracks of $0.2 \mathrm{~mm}$ width (Jonkers et al., 2010). In this research alkaline resistant bacteria (Bacillus Subtilis) is used. This type of bacteria is readily available in UAE region.

Other researcher used different techniques to deal with the healing issues of the concrete cracks. Chemical agent is used to seal the cracks in the concrete (Todar, 2009). Al-Nasra (2013a) explored adding super absorbent polymer to concrete mix. The study focused on the effect of this special chemical agent on the insulation capability of plain concrete. The study showed that the added polymer improves the insulation quality of the concrete. The super-absorbent polymer absorbs water up to 500 times its weight, while the Ultra-high absorbent polymer absorbs water up to 800 times its weight. The polymer absorbs water in large quantity and slowly releases it with time. This phenomenon can be utilized to provide the concrete with internal curing. The internal curing is very useful, especially in places where the concrete curing is difficult. This study takes advantage of this property of the ultra-high absorbent polymer to provide the concrete with the needed internal curing in the hot and dry climate such as the desert climate. The concrete loses moisture at a faster rate in the desert climate compared with other climates. The properties of the fresh concrete mixed with this special chemical agent (super absorbent polymer or ultra-high absorbent polymer) changes too (Al-Nasra, 2013b). The effect of this agent is also explored on the fresh concrete workability and the concrete consistency (Al-Nasra et al., 2015). The superabsorbent chemical agent transforms into gel when subjected to water. This gel improves the concrete stability by acting as cushioning agent (AlNasra and Daoud, 2017). The used chemical agent absorbs large amounts of water and consequently expands in volume. This increase in volume helps sealing the concrete cracks (Al-Nasra, 2018).

\section{Experimental Studies of the Biological Agent}

\section{Bacillus Subtilis as Self-Healing}

The self-healing agent that should be added to concrete needs to be from an alkaline resistant family as it is known that bacteria can die in high alkaline medium like concrete. Moreover, the main purpose for the addition of bacteria is for it to act as a catalyst in the reaction that changes calcium lactate to calcium carbonate (crack filler) in the presence of water. Spore forming bacteria resists the composition of concrete because, it has a thick- walled cells somewhat homologues to plant seeds. Pervious researches showed that these spores are viable as they can withstand mechanical and chemical stresses and remain in dry state for periods over 50 years (Todar, 2009). Bacillus Subtilis does not negatively affect the concrete characteristics like compressive or tensile strength and workability and it can be found in soil, water, air and decomposing plant matter. In this study the Bacillus Subtilis bacteria is cultivated in the labs using broth which is a nutrientinfused liquid medium used for its growth.

The preparation of bacteria starts with mixing water with the provided powder broth which results in the liquid broth formation that is suitable for bacteria cultivation. Then, two Bacillus Subtilis petri dishes stored at different temperatures were cultivated; one was frozen at $-20^{\circ} \mathrm{C}$ that gave many small size colons whereas the other one refrigerated at $4^{\circ} \mathrm{C}$ gave lesser number of larger size colons. Thus, the larger colons were chosen for this study. Around two colons are removed from the petri dish and added to the liquid broth beaker. A total number of four liquid broth containers were made for the experiment purposes and the one with the closest defined Bacillus Subtilis concentration was selected. The beakers are then incubated at $37^{\circ} \mathrm{C}$ and at $230 \mathrm{rpm}$ for $16 \mathrm{~h}$. Then, the beakers are stored at $4^{\circ} \mathrm{C}$ until the concrete mixing time. The concentration was chosen by the process of spectrophotometer as shown in Fig. 1. The limiting factor in this study was 100 grams of calcium lactate. The most applicable concentration of bacteria was found to be $3.73 \times 108$ per 100 grams of calcium lactate. Finally, centrifugation at $1000 \mathrm{rpm}$ is carried out before mixing with the concrete. The supernatant is removed and the bacteria is mixed with its food (Calcium Lactate).

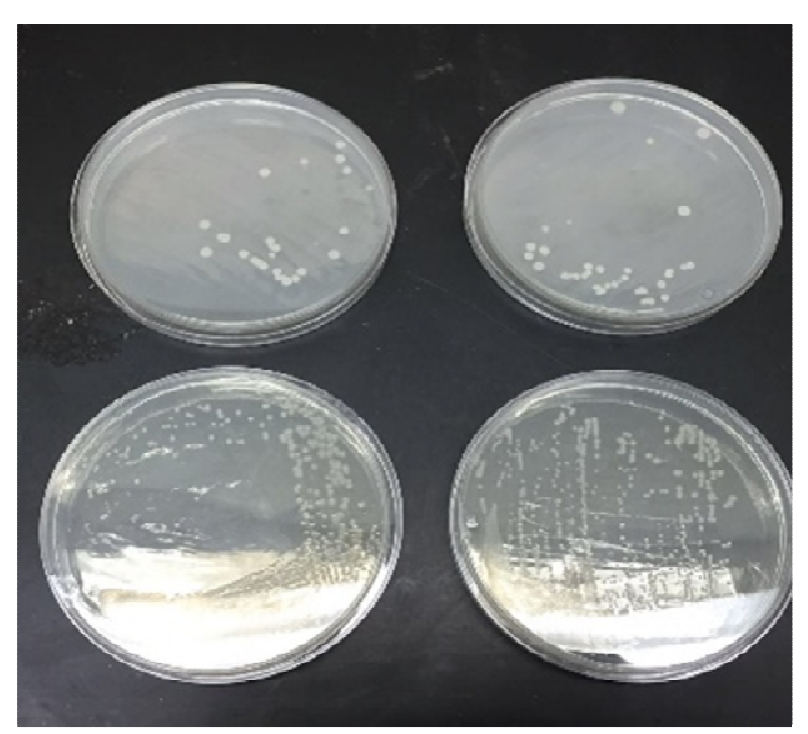

Fig. 1: Bacillus Subtilis petri dishes, the top two are frozen and the bottom two are refrigerated 
Moisture is the trigger of activating this bacterium as it enters through the early stage cracks. The width of cracks that Bacillus Subtilis heal must be less than 0.2 $\mathrm{mm}$. Bacillus Subtilis spores react with Calcium lactate in the presence of moisture to form the filler material Calcium Carbonate (limestone). In previous studies, the effect of adding other organic bio-mineral precursor materials such as yeast extract, peptone and calcium acetate has been investigated. However, those precursor materials do not seem to be very useful in this study due to substantial decrease in concrete compressive strength.

\section{Bacillus Subtilis Concrete Mix}

To investigate the effect of Bacillus Subtilis, a traditional two sets of concrete specimens were prepared (Table 1) and each specimen set consists of two cylinders of $15 \times 300 \mathrm{~mm}$ size and one cube of $100 \times 100$ $\mathrm{mm}$ size. The first set has been considered as the control sample and the second set contains the biological agent which is Alkaline resistant bacteria and calcium lactate. $20 \%$ of the fine aggregate (2-4 $\mathrm{mm}$ in diameter) has been replaced by light expanded clay. Trial mixes were done to obtain the replacing percentage of fine aggregate in the mix without affecting the compressive strength and it was observed that the substitution of more than $20 \%$ of the fine material by light weight clay caused substantial decrease in compressive strength.

In the modified concrete mix set, the concentration of the bacteria was limited to the available amount of calcium lactate. The limiting factor, which is $100 \mathrm{~g}$ of calcium lactate, was carefully dissolved in $500 \mathrm{~mL}$ of water to make sure it mixes well with the bacteria. The specimens had the same composition of fine aggregate, coarse aggregate, expanded clay particles, cement and water.

\section{Bacillus Subtilis Concrete Curing}

The curing for the concrete is the most important stage of its life cycle. Building a structure with a sustainable concrete that can withstand the loading of various types such as the dead load, live load and wind load for the longest possible period of time needs adequate curing. Normal concrete gains $76 \%$ of its strength within 28 days of curing at room temperature. The necessity for water in the concrete arises during this period from the fact that cement reacts with the water to produce the bonding paste.

Table 1: Concrete mix ingredients

\begin{tabular}{lcc}
\hline Material & Weight $(\mathrm{kg})$ & Weight $(\mathrm{N})$ \\
\hline Light Weight Expanded & 2.3 & 22.5 \\
Clay (2-4 mm) & & \\
Fine Aggregate & 9.2 & 90.2 \\
Coarse Aggregate & 15.9 & 155.9 \\
Cement & 6.1 & 59.8 \\
Water & 2.4 & 23.5 \\
Total & 35.9 & 352.1 \\
\hline
\end{tabular}

In this study, boiling curing method at $100^{\circ} \mathrm{C}$ for three hours and then at room temperature for another three hours was used in this study to accelerate the gaining of the compressive strength in concrete. The following equation shows the concrete of 28 days strength:

$R 28=8.09+1.64 R a$

Where:

$R 28=$ The predicated compressive strength in 28 days

$R a=$ The accelerated compressive strength after curing

\section{Water Content and Air Content}

The hydration of cement is controlled by the water/cement ratio that can be determined by concrete mix design calculations. Adjusting this design calculations to fit the absorption of the added ingredient (expanded clay 2 to $4 \mathrm{~mm}$ in diameter) was necessary. Water absorption content tests showed that the absorption rate is $1.19 \%$. Although the expanded clay water absorption was relatively low, it still made a huge difference in the design mix. Slump test has also been used to check the workability of concrete. The air content test of the same batch showed $5 \%$ air voids content.

\section{Compressive Strength Test}

The results from the compressive strength test showed that the bacterial concrete specimens were able to handle higher compressive stress when compared to the control traditional concrete specimens. Concrete samples (with and without biological agent) were fully broken to determine the maximum load capacity. A cyclic load was applied on different set of samples, by loading and unloading to $50 \%$ of maximum strength for a total number of five times with 5 min rest in between each cycle to induce minor cracks in the specimens. After seven days the specimen was tested for the compressive strength. As shown in Fig. 2, the compressive strength in the bacteria specimens exhibited higher values compared to the control concrete compressive strength specimens. The bacteria have been activated by water moisture from the environment which filled the micro-cracks. Then, the bacteria transformed the calcium lactate to white precipitate calcium carbonate according to the following equation:

$$
\mathrm{Ca}\left(\mathrm{C}_{3} \mathrm{H}_{5} \mathrm{O}_{2}\right)_{2}+7 \mathrm{O}_{2} \rightarrow \mathrm{CaCO}_{3}+5 \mathrm{CO}_{2}+5 \mathrm{H}_{2} \mathrm{O}
$$

Figure 3 shows the calcite precipitating bacteria producing calcite based binding material to seal the induced micro-cracks in the concrete mass. The photo in the top side of the figure shows the calcite precipitant being created, while the photo in the bottom side of the figure shows the product of the biological agent inside the biological agent specimen. 


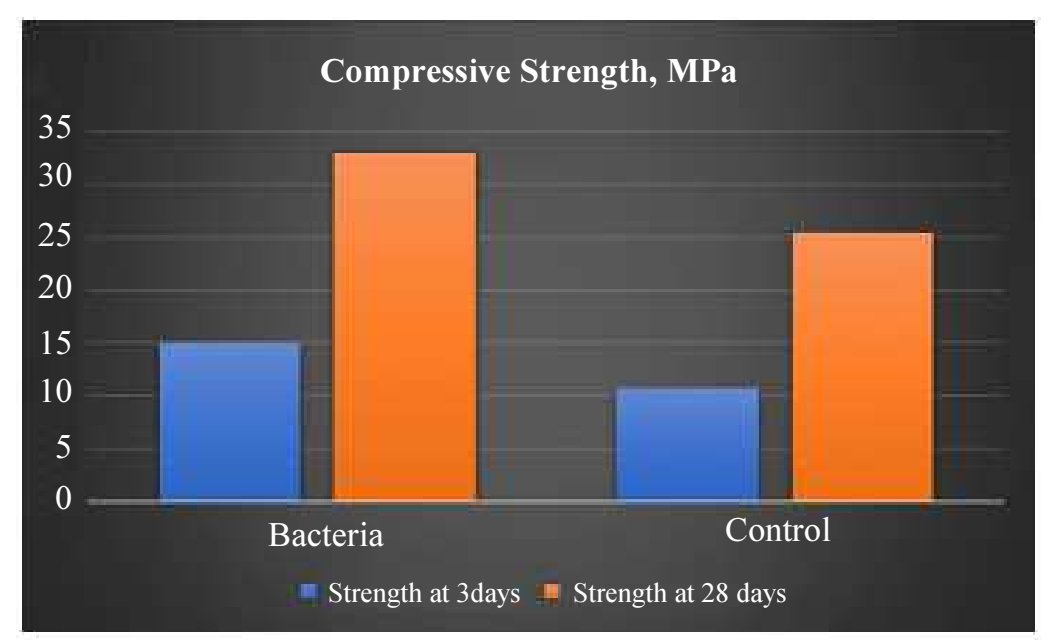

Fig. 2: Compressive Strength at 7 days and 28 days

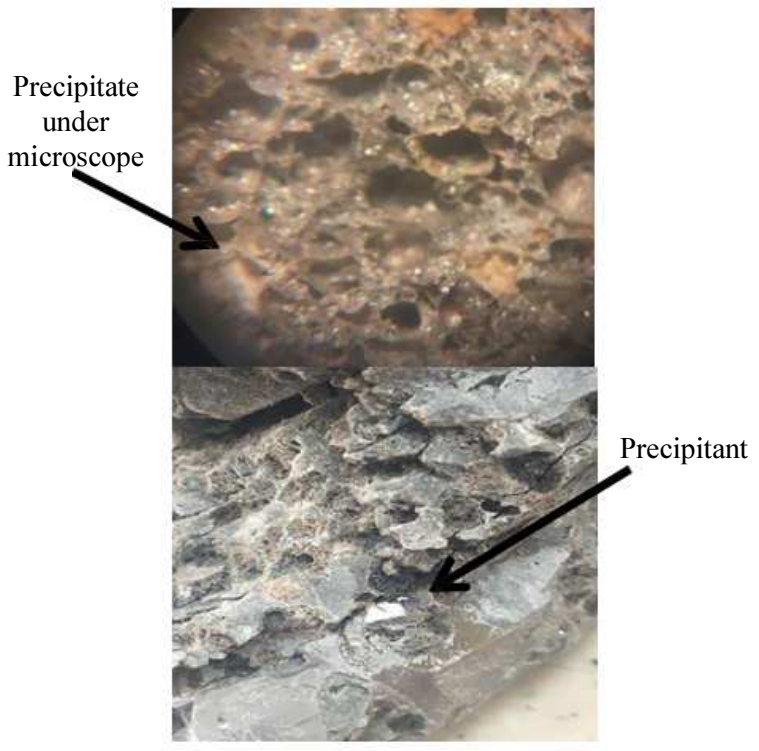

Fig. 3: Calcite precipitating bacteria in process of sealing micro-cracks

\section{Experimental Studies of the Ultra-High Absorbent Polymer (UHAP)}

\section{Testing the Compressive Strength of UHAP Concrete}

Figure 4 shows the experimental set-up of the concrete compressive test. Eight concrete cubes were prepared for the compressive test. Five out of eight contains UHAP at different values. These values are expressed as percentage of the Portland cement by weight. The percentages used here are $0.00,0.10,0.20$, 0.40 and $0.60 \%$. The other three cubes were prepared and cured according to the ASTM standards. These cured cubed contained no UHAP. They are used as controlling samples and for comparison purposes. The average of the compressive strength of these three cubes is used to study the effectiveness of the UHAP as internal curing agent in hot and dry desert climate. The average of these fully cured cubes of $0 \%$ UHAP is measured to be $20.163 \mathrm{MPa}$. The other five cubes were not cured, but left exposed to hot desert temperature and high humidity. The five cubes were not exposed to the direct sun rays but left in the shade.

\section{Concrete Mix and Curing of UHAP Concrete}

The UHAP plays significant role in providing the concrete with the moisture it needs for internal curing. The UHAP absorbs water in large quantities and releases it slowly in the concrete mass. This helps increasing the strength of the concrete especially in the hot desert climate. Figure 5 shows the increase in the concrete compressive strength because of adding UHAP to the concrete mix. The increase in the amount of the UHAP increases the supply of the water needed for the internal curing, at the same time increases the volume of voids occupied by the UHAP. Excessive amount of UHAP becomes harmful to the concrete compressive strength due to generating of excessive void space in the concrete mass. Figure 6 shows the effect of the UHAP on the concrete compressive strength expressed as percentage of the average regular standard concrete samples. The average of the compressive strength of the three cubes of $0.00 \%$ UHAP cured according to the ASTM standard test is used in this study to evaluate the effectiveness of adding the UHAP to the concrete mix. The excessive void space created by UHAP decreases the concrete strength. As can be seen from the Fig. 5 and the Fig. 6 the optimum amount of UHAP is approximately $25 \%$. This optimum value generates an efficiency of $83 \%$ compared to the standard curing tests. The samples of UHAP were left for seven days exposed to the hot summer temperature and humidity. The temperature ranged between $23^{\circ} \mathrm{C}$ to $39^{\circ} \mathrm{C}$ and the humidity ranged between $57 \%$ to $87 \%$. 


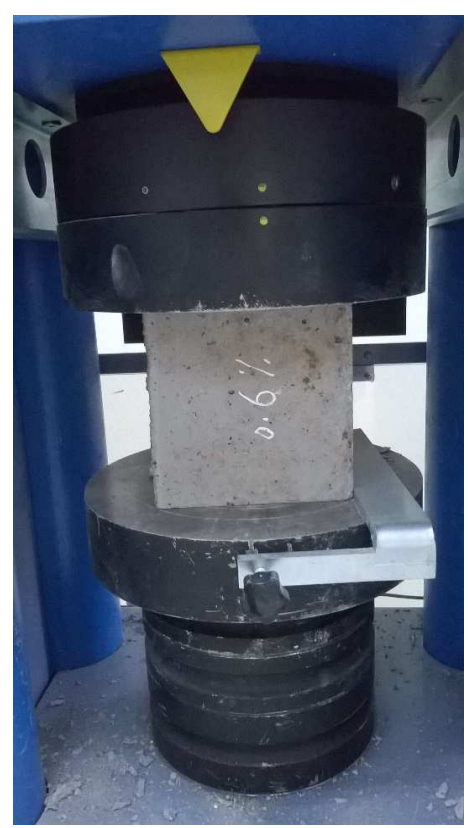

Fig. 4: Compressive strength test

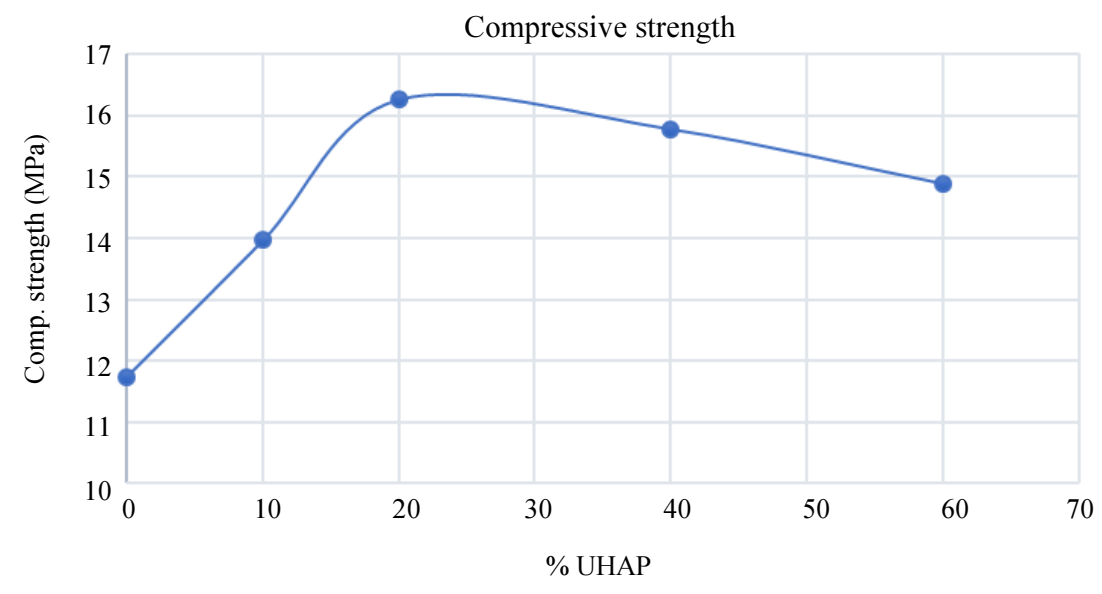

Fig. 5: Effect of UHAP on the compressive strength of concrete

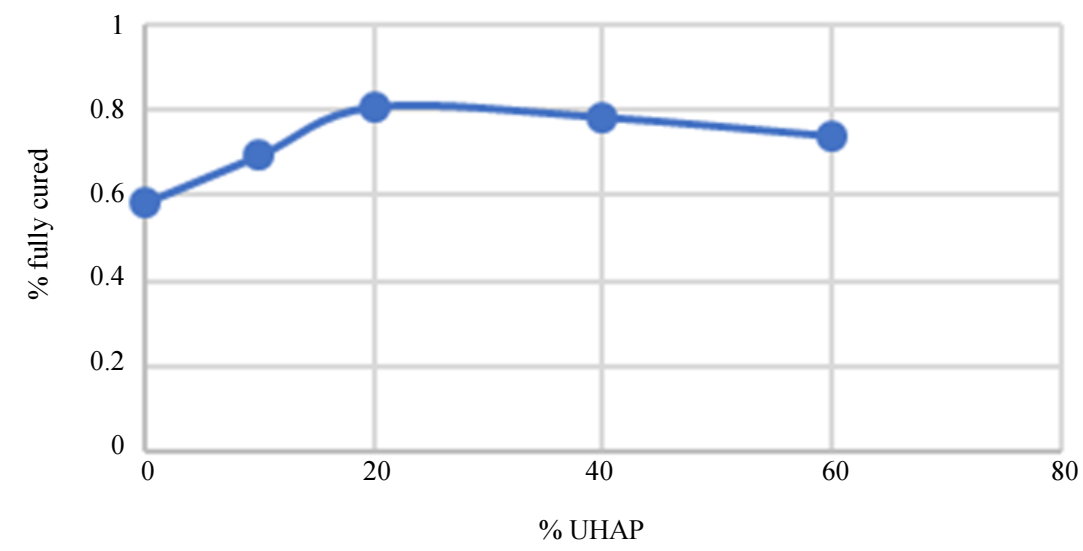

Fig. 6: Compressive strength of concrete mixed with UHAP expressed as percentage of the standard cured samples 


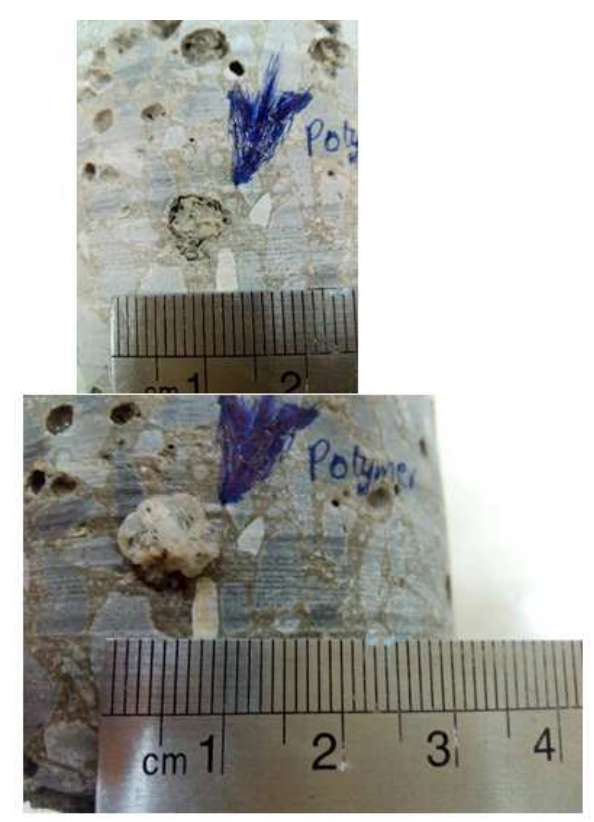

Fig. 7: Effect of subjecting the concrete to moisture on the imbedded UHAP polymer, the picture on the top is before and the picture on the bottom is after

Figure 7 shows the embedded UHAP in the concrete mass. The top side of the figure shows a dry sample, while the bottom side of the figure shows the same sample subjected to moisture. As can be seen from the figure the UHAP starts to absorb water and increase in volume. The UHAP retains large amount of water at a time. This absorbed water can be release at a slow rate to the surrounding materials. In this study, this phenomenon is utilized to provide the concrete with the water it needs for the chemical reaction at its early age.

\section{Conclusion}

Results of this study showed that concrete specimens with the biological agent (Bacillus Subtilis) exhibited an increase in compressive strength, when compared to specimens with no biological agent. This could be considered as a sign of minor cracks healing. The conversion of calcium lactate to white precipitate (calcium carbonate) indicated that the bacteria was functioning as intended. As a part of future work, more experiments will be conducted to investigate the selfhealing process of the concrete cracks with width above $0.2 \mathrm{~mm}$. Using Ultra-High Absorbent Polymer (UHAP) as internal curing agent is proven to be effective especially in hot and dry desert climate. Adding UHAP increases the compressive strength of concrete to certain limit. An optimum value of UHAP needs to be taken into consideration when using it as internal curing agent. In this study $25 \%$ by weight of the Portland cement of the UHAP gave the best results. This study showed that the internal curing process using UHAP reached an efficiency up to $83 \%$ of the standard curing.

\section{Acknowledgment}

The authors would like to acknowledge the invaluable assistance provided by our laboratories.

\section{Author's Contributions}

Batoul Chamali: Performed laboratory experiments and conducted data analysis of the research. Also, participated in writing the manuscript

Moayyad Al-Nasra and Taher M. Abu-Lebdeh: Provided the research topic and guided the research development, experimental plan and data analysis.

\section{Ethics}

No part of this article may be reproduced without written permission from the publisher or authors

\section{References}

Al-Nasra, M., 2013a. Concrete made for energy conservation mixed with sodium polyacrylates. Int. J. Eng. Res. Applic., 3: 601-604.

Al-Nasra, 2013b. Optimizing the use of sodium polyacrylate in plain concrete. Int. J. Eng. Res. Applic., 3: 1058-10627. Al-Nasra, M. and M. Daoud, 2013. Investigating the use of super absorbent polymer in plain concrete. Int. J. Emerg. Technol. Adv. Eng., 3: 598-603. 
Al-Nasra, M. and M. Daoud, 2017. Study of the ability of cracked concrete to block water flow, concrete mixed with super absorbent polymer. ARPN J. Eng. Applied Sci., 12: 274-281.

Al-Nasra, M., 2018. Study of the self-sealing capability of polymer concrete. ARPN J. Eng. Applied Sci., 13: 1297-1303.

Al-Nasra, M., M. Daoud and T. AbuLebdeh, 2015. The use of the super absorbent polymer as water blocker in concrete structures. Am. J. Eng. Applied Sci., 8: 659-665. DOI: 10.3844/ajeassp.2015.659.665
Jonkers, H.M., A. Thijssen, G. Muyzer, O. Copuroglu and E. Schlangen, 2010. Application of bacteria as self- healing agent for the development of sustainable concrete. Ecol. Eng., 36: 230-235. DOI: 10.1016/j.ecoleng.2008.12.036

Todar, K., 2009. Todar's online textbook of bacteriology. The Genus Bacillus. 